\title{
Subjective efficacy of nasal CPAP therapy in obstructive sleep apnoea syndrome: a prospective controlled study
}

\author{
J.L. Kiely, M. Murphy, W.T. McNicholas
}

\begin{abstract}
Subjective efficacy of nasal CPAP therapy in obstructive sleep apnoea syndrome: a prospective controlled study. J.L. Kiely, M. Murphy, W.T. McNicholas. (C) ERS Journals Ltd 1999.
\end{abstract}

ABSTRACT: The response to nasal continuous positive airways pressure (nCPAP) of a wide variety of symptoms recognized to be associated with obstructive sleep apnoea syndrome (OSAS) was examined.

Fifty-six consecutive patients with OSAS, confirmed by polysomnography (mean (sD) apnoea-hypopnoea index (AHI) 49.6 (22.6) events $h^{-1}$, Epworth score $15.4(5.0)$ ), were asked to complete paired symptom evaluation questionnaires, before treatment and again after 4 months of nCPAP. The response rate was $80 \%$. A control group of 21 consecutive OSAS patients of similar age, body mass index (BMI), AHI and Epworth score to the treated group but managed with conservative measures, completed the same questionnaires on two occasions, 4 months apart.

The nCPAP-treated group showed significant reductions (Wilcoxon matched pairs test) in the symptoms of daytime sleepiness, restless sleep, heartburn, nocturia, enuresis, headache and nocturnal sweating, whereas controls showed no significant changes in these symptoms. There were no changes in BMI, smoking, alcohol consumption or exercise habits in either group.

It was concluded that, in addition to improvements in symptoms of daytime sleepiness and restless sleep, a wide range of other symptoms may improve significantly with nasal continuous positive airways pressure therapy.

Eur Respir J 1999; 13: 1086-1090.
Respiratory Sleep Laboratory and the Dept of Respiratory Medicine, St Vincent's University Hospital, Dublin, Ireland.

Correspondence: W.T. McNicholas Dept of Respiratory Medicine St Vincent's University Hospital Elm Park

Dublin 4

Ireland

Fax: 35312697949

Keywords: Nasal continuous positive airways pressure

obstructive sleep apnoea syndrome symptoms

Received: March 241998

Accepted after revision November 261998

The authors acknowledge funding received from the Irish Health Research Board for this study.
Obstructive sleep apnoea syndrome (OSAS) affects $1-$ $4 \%$ of adults in Europe and North America [1, 2]. Treatment with nasal continuous positive airways pressure (nCPAP) can abolish apnoeas during sleep and has been shown to greatly reduce the excessive daytime sleepiness (EDS) $[3,4]$ that is a major symptom of OSAS. However, OSAS has been reported to be associated with a wide variety of other symptoms, including heartburn [5], nocturia [6], adult nocturnal enuresis [7], and nocturnal sweating [8], but there are little data available on the impact of nCPAP on these. Therefore, a prospective assessment of the subjective impact of nCPAP therapy on a wide range of symptoms in patients with moderate to severe OSAS was performed.The response to nCPAP was compared with a control group of patients with OSAS and similar clinical features, managed with conservative measures.

\section{Methods}

Fifty-six consecutive patients, with a diagnosis of OSAS previously established by full overnight polysomnography (PSG) using standard techniques [9], and who were admitted from the hospital waiting list for nCPAP therapy, completed a written pretreatment questionnaire. This questionnaire contained 23 multiple part questions aimed to assess sleep quality perception and symptoms of OSAS such as snoring, nocturnal choking and witnessed ap- noeas. A range of other questions were asked, relating to abnormal motor activity during sleep; changes in personality including mood, irritability and depression; nocturnal sweating; hypnagogic hallucinations; sexual problems including libido and impotence; sleeping position in bed, oesophageal reflux; nocturia and enuresis; nasal symptoms; menstrual status (in women); headache; hearing acuity; ankle swelling; eating habits (including alcohol and nicotine consumption); and whether or not the patient slept apart from his/her partner.

The scoring system for the questions was a 3 point ordinal scale, a score of 0 indicating a "No" answer, 1 indicating a minor degree or occasional occurrence of the symptom, and 2 indicating a major problem or frequent occurrence of the symptom. In the case of snoring, a 4 point scale was used. The questionnaire was initially administered in the presence of a laboratory technician and took $\sim 20$ min to complete. Following a period of 4 months on nCPAP therapy, follow-up questionnaires were sent by post to all the patients. These questionnaires had the same structure and content as the pretreatment questionnaire, but the stems of the questions were modified to include the phrase "since commencing nCPAP". Those patients who did not return questionnaires despite repeated requests by postal enquiry, were contacted by telephone and their treatment status (continuing to use nCPAP or not) was identified. It was not possible to administer the questionnaire by phone due to its length. 
A control group of 21 consecutive patients was also recruited, consisting of patients with diagnosed OSAS, who were on the hospital waiting list for nCPAP therapy. Therefore, the control group was drawn from a similar patient population as the patient group, and had similar age, body mass index (BMI), Epworth scores [10] and apnoea-hypopnoea index (AHI) as the nCPAP group (table 1). These patients completed the same questionnaire at baseline, and again on average 4 months later, and were carefully instructed at the time of the initial questionnaire on conservative measures designed to improve OSAS, such as diet, exercise, sleeping position and alcohol avoidance. Thus, the study design allowed a comparison of the efficacy of nCPAP with conservative measures in controlling OSAS-related symptoms.

\section{Statistical analysis}

Between-group comparisons were tested by the MannWhitney test and within subject paired comparisons were performed using the Wilcoxon matched pairs test. A $p \leq$ 0.05 value indicates statistical significance.

\section{Results}

The response rate to the follow-up questionnaire was $80 \%$, with 45 post-treatment questionnaires returned for analysis. Four $(7 \%)$ patients who returned questionnaires had discontinued nCPAP. Of the remaining 11 patients who had not replied to the follow-up questionnaire despite reminders, 10 were contacted by telephone: five (9\%) continued to use nCPAP with reported symptomatic benefit, while five $(9 \%)$ had discontinued treatment due to lack of perceived benefit or intolerance of the device. One patient could not be contacted and his treatment status remains unknown. Thus, some form of follow-up assessment was possible in $98 \%$ of patients. The compliance rate, assessed from the number of patients using nCPAP at 4 months, was $82 \%$.

In an effort to approximate an intention-to-treat analysis, the four patients who returned follow-up questionnaires but had discontinued nCPAP together with those five patients who, when contacted by telephone, indicated that they had discontinued nCPAP because of lack of perceived benefit were included. Since there were no follow-up questionnaires on these five patients, their pre-treatment questionnaires were duplicated as follow-ups to reflect their reported lack of benefit from nCPAP. It was regarded as inappropriate to analyse the remaining five patients in this fashion, since each of these patients had clearly indicated a subjective benefit from nCPAP on telephone interview, although they had failed to return follow-up questionnaires.

Table 1. - Characteristics of treated and control groups

\begin{tabular}{lcccc}
\hline Group & $\begin{array}{c}\text { Age } \\
\text { yrs }\end{array}$ & $\begin{array}{c}\mathrm{BMI} \\
\mathrm{kg} \cdot \mathrm{m}^{-2}\end{array}$ & $\begin{array}{c}\text { Epworth } \\
\text { score }\end{array}$ & $\begin{array}{c}\mathrm{AHI} \\
\text { events } \cdot \mathrm{h}^{-1}\end{array}$ \\
\hline Treatment & $51.8(10.5)$ & $32.6(8.1)$ & $15.4(5.0)$ & $49.6(22.6)$ \\
Control & $53.2(7.6)$ & $31.0(4.8)$ & $13.6(4.3)$ & $40.4(17.9)$ \\
\hline
\end{tabular}

Data presented as mean (SD). BMI: body mass index; AHI: apnoea-hypopnoea index.
Although mean values tended to be slightly higher in the nCPAP-treated group, there were no statistically significant differences between the treatment and control groups for age, BMI, AHI and Epworth scores (table 1). Furthermore, no significant differences were observed between the treatment and control groups for each symptom at baseline. There was no reported or observed change in weight, alcohol consumption, smoking or exercise habits among patients, in either control or nCPAP groups on follow-up.

A comparison of the control group baseline and followup questionnaires indicated no significant improvement, nor any trend towards improvement, in symptom scores following general lifestyle advice. In contrast, the treated group (which consisted of 41 patients still using nCPAP who returned questionnaires together with the additional 9 patients who had discontinued the device) showed highly significant improvements in several symptoms on the follow-up questionnaire (table 2). Four patients reported enuresis prior to commencing nCPAP which resolved following commencement of nCPAP therapy. Thirteen patients $(29 \%)$ reported increased libido following nCPAP commencement whereas 24 patients (53\%) had considered themselves to have reduced libido on baseline pretreatment questionnaires. Twenty patients $(44 \%)$ reported being less irritable on nCPAP therapy compared to 26 $(58 \%)$ who had reported being irritable prior to diagnosis and treatment. BMI did not change in the treatment group, being (mean (SD)) $32.6(8.1) \mathrm{kg} \cdot \mathrm{m}^{-2}$ pre-treatment compared to $32.7(8.0) \mathrm{kg} \cdot \mathrm{m}^{-2}$ at the time of follow-up 4 months later.

The characteristics of the five patients who did not return the follow-up questionnaire and had discontinued nCPAP due to lack of benefit were examined. In comparison to those who replied to the repeat questionnaire, they were significantly less obese (mean (SD) BMI=26.7 (3.15) versus $\left.33.3(8.6) \mathrm{kg} \cdot \mathrm{m}^{-2}, \mathrm{p}<0.05\right)$ and tended to be less sleepy and less likely to complain of nocturnal sweating at baseline. These patients were also significantly more likely to sleep in a separate room from their partners and consume less alcohol. However, AHI in this group were not significantly different from those who replied. Excluding these five patients from the data analysis did not significantly change any of the statistical findings reported in table 2.

\section{Discussion}

These findings indicate a clear subjective benefit of nCPAP in alleviating many of the symptoms affecting patients with OSAS. While there have been a considerable number of previous studies that have evaluated the efficacy of nCPAP in treating OSAS, there appears to be no previous report that has evaluated the impact of nCPAP on such a wide range of symptoms in patients with severe OSAS using a prospective controlled design.

Previous reports have documented improvements in daytime alertness with nCPAP, some of which were retrospective or cross-sectional and uncontrolled in design [11-14], others prospective but uncontrolled [3, 15-18], and others randomized, prospective, and controlled [4, 19-21]. Other reports have focused on the neuropsychological effects of nCPAP therapy, and have demonstrated improvements in indices of depression $[22,23]$ and mood [24], although some neuropsychological deficits appear 
Table 2. - Summary of questionnaire data before and after institution of nasal continuous positive airway pressure therapy

\begin{tabular}{|c|c|c|c|}
\hline \multirow[b]{2}{*}{$\begin{array}{l}\text { Question } \\
\text { Do you (have): }\end{array}$} & \multicolumn{2}{|c|}{$95 \%$ confidence interval } & \multirow[b]{2}{*}{$\begin{array}{l}\text { Wilcoxon } \\
\text { p-value }\end{array}$} \\
\hline & Pre & Post & \\
\hline Snoring & $2.5-2.9$ & $0.4-0.9$ & $<0.0001$ \\
\hline Witnessed apnoeas & $1.5-1.8$ & $0.1-0.5$ & $<0.0001$ \\
\hline Excessive Daytime Fatigue & $1.3-1.7$ & $0.4-0.9$ & $<0.0001$ \\
\hline Epworth Score-units & $14.0-17.6$ & $3.8-6.3$ & $<0.0001$ \\
\hline Difficulty in Concentration & $0.7-1.1$ & $0.4-0.8$ & $<0.05$ \\
\hline Memory & $0.7-1.1$ & $0.4-0.8$ & NS \\
\hline Orientation on awakening & $0.3-0.7$ & $0.1-0.5$ & NS \\
\hline Frequent waking during the night & $0.8-1.3$ & $0.5-0.9$ & $<0.05$ \\
\hline Difficulty in getting a full night's sleep & $0.7-1.2$ & $0.4-0.8$ & $<0.005$ \\
\hline Poor sleep quality & $1.3-1.7$ & $0.4-0.8$ & $<0.0001$ \\
\hline Waking at night with a choking feeling & $0.3-0.7$ & $0.0-0.3$ & $<0.05$ \\
\hline Restless sleep & $0.6-1.1$ & $0.3-0.6$ & $<0.05$ \\
\hline Restless legs while asleep & $0.3-0.7$ & $0.1-0.5$ & NS \\
\hline Sleepwalking & $0.0-0.1$ & $0.0-0.1$ & NS \\
\hline Depression & $0.4-0.8$ & $0.2-0.6$ & NS \\
\hline Nocturnal sweating* & $0.3-0.7$ & $0.2-0.4$ & 0.05 \\
\hline Hypnogogic hallucinations & $0.2-0.6$ & $0.1-0.3$ & $<0.01$ \\
\hline Heartburn & $0.4-0.8$ & $0.1-0.4$ & $<0.01$ \\
\hline Heartburn in bed & $0.2-0.6$ & $0.0-0.3$ & $<0.01$ \\
\hline Awoken with heartburn & $0.1-0.5$ & $0.0-0.1$ & $<0.01$ \\
\hline Get up at night to pass urine & $1.1-1.5$ & $0.4-0.8$ & $<0.0001$ \\
\hline Daily frequency of passing urine $n$ & $1.5-1.9$ & $1.5-2.0$ & NS \\
\hline Nightly frequency of passing urine $n$ & $1.3-1.9$ & $0.8-1.4$ & $<0.05$ \\
\hline Blocked nose & $0.8-1.3$ & $0.5-0.9$ & $<0.01$ \\
\hline Headache on rising in the morning** & $0.1-0.5$ & $0.0-0.2$ & $<0.05$ \\
\hline Awaken with severe headache at night & $0.0-0.2$ & $0.0-0.1$ & NS \\
\hline Headache after daytime nap & $0.0-0.3$ & $0.0-0.2$ & NS \\
\hline Reduction in hearing & $0.3-0.6$ & $0.2-0.6$ & NS \\
\hline Ankle swelling & $0.2-0.5$ & $0.1-0.4$ & NS \\
\hline Smoking habit yes $=1$, no $=0$ & $0.1-0.3$ & $0.1-0.3$ & NS \\
\hline Weekly alcohol consumption units & $6.4-13.6$ & $7.8-16.3$ & NS \\
\hline Regular exercise yes $=1, \mathrm{no}=0$ & $0.2-0.5$ & $0.3-0.6$ & NS \\
\hline Different rooms from partner yes $=2, n o=1$ & $1.2-1.6$ & $0.9-1.4$ & $<0.05$ \\
\hline
\end{tabular}

*: "Bad enough to require a change of clothing or bedclothes"; **: "without having consumed alcohol". Answer scores based on a 3 point scale (0-2) as indicated in text, except snoring (4 point scale), and unless otherwise indicated in the table. Patients without partners answered 0 (not applicable) to the last question in the table.

to persist, perhaps reflecting hypoxic brain damage [25]. The present data reporting improvements in both mood and concentration together with reduced irritability are in keeping with these previous reports. Although some of these studies were prospective, none included a control group.

Furthermore, the best designed studies, involving a prospective, randomized, and controlled design, have either studied patients with mild OSAS $[20,21]$, or alternatively included a range of OSAS severity where a large proportion of patients had mild or moderate disease [4, 19]. While these particular studies have demonstrated a benefit from nCPAP therapy, this benefit appears to have been less dramatic than that observed with many of the uncontrolled studies cited above. The level of improvement seen in daytime sleepiness in the present study was similar to that reported in many of these uncontrolled studies [3, 11-15], but the average severity of OSAS was more severe than in previous randomized controlled studies, and similar to most of the uncontrolled studies. However, the lack of improvement in the present control group indicates that the improvement seen in the nCPAP group was a real effect of therapy, and the prospective design involving consecutive patient selection in both groups minimizes the possibility of selection bias.

The limitations of the present control group are recognized, particularly that the control and patient groups were not randomized, but it was believed that the particular choice remains valid for a number of reasons. Firstly, the controls were similar to the patients in the important variables of age, sex, BMI, AHI, and severity of sleepiness as determined by Epworth scores.

Secondly, while it is recognized that a randomized control group would have been preferable, it was felt that a randomized study design where patients with such severe OSAS had nCPAP therapy withheld for 4 months would have raised ethical concerns. The mean AHI in the nCPAP group was 50 events $\cdot \mathrm{h}^{-1}$ indicating that most patients had severe OSAS. The delays involved in instituting nCPAP therapy at the authors' institution caused by inadequate facilities were utilized to develop a control group that would be similar to the patient group in most respects. The patient population consisted of consecutive patients admitted from the hospital waiting list for nCPAP therapy who were then evaluated 4 months after institution of nCPAP therapy, whereas the control group consisted of 
consecutive patients placed on the waiting list for nCPAP therapy who were evaluated at the time of going on the waiting list and again 4 months later, prior to the institution of nCPAP. Thus, the two groups were drawn from a similar patient population. While the control group had smaller numbers than the nCPAP group, it is not believed that this difference detracts from the findings since no trends were observed towards change in the control group at follow-up.

Thirdly, while it is recognized that some bias may have been introduced by the fact that control patients were awaiting nCPAP therapy, considerable efforts were made to minimize such bias by carefully educating patients in conservative measures to help OSAS such as weight reduction, sleep hygiene, body position, and alcohol avoidance. It was indicated to each patient that such measures could help OSAS considerably, and could also obviate the necessity for nCPAP in some cases. Thus, every effort was made to ensure that control patients provided an adequate reflection of the impact of conservative therapy over the study period.

Previous reports have indicated that gastro-oesophageal reflux (GOR) may induce respiratory abnormalities during sleep [26] and seems to be common in OSAS patients [27]. There is limited and conflicting data available on the mechanisms of interaction between nCPAP and GOR [5, 27] and less still on whether actual symptoms of heartburn change with nCPAP therapy. However, there are good physiological reasons why symptoms of heartburn may improve with the treatment of OSAS since the abolition of the repetitive Mueller manoeuvres associated with obstructive apnoeas might be expected to reduce oesophageal reflux.

Plasma renin activity and aldosterone levels are reduced, and atrial natriuretic peptide (ANP) levels are elevated in OSAS [28, 29] resulting in increased nocturnal diuresis [30] which may result in nocturnal polyuria $[6,31]$ and enuresis. These disturbances were normalized with nCPAP in OSAS [29], which would be expected to benefit nocturia and enuresis. The present data clinically reflect these physiological observations in that nocturnal urinary symptoms diminish significantly with nCPAP treatment. Similarly, the symptom of profuse nocturnal sweating was noted to significantly improve with nCPAP which may reflect the reduction in sympathetic tone that has been demonstrated to follow treatment of OSAS with nCPAP [32].

The reported improvements in libido following nCPAP are in keeping with previous reports on OSAS [33]. Headache on rising in the morning (without having consumed alcohol) was also significantly reduced with nCPAP treatment. The mechanism whereby morning headache occurs in OSAS is not well understood but is likely to be multifactorial [34]. Morning headache is now a wellrecognized feature of OSAS, and a full investigation of headache of unknown cause may require exclusion of OSAS as a possible cause [35].

Nasal CPAP therapy might be expected to be socially unacceptable to the bed partner because of the potential intrusiveness of the device. However, the present data suggest the opposite in that patients reported a significant decrease in sleeping in separate rooms from their bed partner following institution of nCPAP. These data support prior findings related to acceptance of nCPAP therapy by bed partners of patients with OSAS [18].
A particular strength of the present study is that followup assessment was achieved in $98 \%$ of patients with $80 \%$ completing both initial and follow-up questionnaires. Furthermore, the possibility of bias in favour of nCPAP was minimized by including those patients who discontinued nCPAP in the analysis, and thus approximated an intention-to-treat analysis. Follow-up data for those five patients who had subjectively good responses reported by phone interview were not included, which may, if follow-up questionnaires had been available have influenced the results more positively toward a benefit with nCPAP.

It was concluded that there are many subjective benefits experienced by obstructive sleep apnoea syndrome patients treated with nasal continuous positive airway pressure, over and above the commonly addressed impact on daytime sleepiness. These data suggest that nasal continuous positive airway pressure therapy has a sustained beneficial impact on the overall quality of life of patients affected with obstructive sleep apnoea syndrome.

Acknowledgements: The authors would like to acknowledge the contribution of P.C. Deegan to this study.

\section{References}

1. Partinen M. Epidemiology of sleep disorders. In: Kryger MH, Roth T, Dement WC, eds. Principles and Practice of Sleep Medicine. 2nd Edn. Philadelphia, WB Saunders, 1994; pp. 437-452.

2. Young T, Palta M, Dempsey J, Skatrud J, Weber S, Badr $\mathrm{S}$. The occurrence of sleep-disordered breathing among middle-aged adults. N Engl J Med 1993; 328: 1230-1235.

3. Hardinge FM, Pitson DJ, Stradling JR. Use of the Epworth sleepiness scale to demonstrate response to treatment with nasal continuous positive airways pressure in patients with obstructive sleep apnoea. Respir Med 1995; 89: 617-620.

4. Engleman HM, Martin SE, Deary J, Douglas NJ. Effect of continuous positive airway pressure treatment on daytime function in sleep apnoea/hypopnoea syndrome. Lancet 1994; 343: 572-575.

5. Graf KI, Karaus M, Heinemann S, Korber S, Dorow P, Hampel KE. Gastroesophageal reflux in patients with sleep apnea syndrome. Z Gastroenterol 1995; 33: 689693.

6. Pressman MR, Figueroa WG, Kendrick-Mohamed J, Greenspon LW, Peterson DD. Nocturia: a rarely recognized symptom of sleep apnea and other occult sleep disorders. Arch Interm Med 1996; 156: 545-550.

7. Flemons WW, Tsai W. Quality of life consequences of sleep-disordered breathing. J Allergy Clin Immunol 1997; 99: S750-S756.

8. McGinty D. Sleep disorders in the elderly: rationale for clinical awareness. Geriatrics 1987; 42: 61-62, 65-69, 72.

9. Rechtschaffen A, Kales A. A manual of standardized terminology, techniques and scoring system for sleep stages of human subjects. Washington DC, US Government Printing Office, Public Health Service, 1968.

10. Johns MW. A new method for measuring daytime sleepiness: the Epworth sleepiness scale. Sleep 1991; 14: 540545 . 
11. Sullivan CE, Issa FG, Berthon-Jones M, McCauley VB, Costas LJ. Home treatment of obstructive sleep apnoea with continuous positive airway pressure applied through a nose mask. Bull Eur Physiopathol Respir 1984; 20: 4954.

12. Hoffstein V, Viner S, Mateika S, Conway J. Treatment of obstructive sleep apnea with nasal continuous positive airway pressure, patient compliance, perception of benefits, and side effects. Am Rev Respir Dis 1992; 145: 841-845.

13. McEvoy RD, Thornton AT. Treatment of obstructive sleep apnea syndrome with nasal continuous positive airway pressure. Sleep 1988; 7: 313-325.

14. Engleman HM, Asgari-Jirhandeh N, McLeod AL, Ramsay CF, Deary IJ, Douglas NJ. Self-reported use of CPAP and benefits of CPAP therapy: a patient survey. Chest 1996; 109: 1470-1476.

15. Sforza E, Krieger J. Daytime sleepiness after long-term continuous positive airway pressure treatment in obstructive sleep apnea syndrome. J Neurol Sci 1992; 110: 21-26.

16. Sforza E, Lugaresi E. Daytime sleepiness and nasal continuous positive airway pressure therapy in obstructive sleep apnea syndrome patients: effects of chronic treatment and 1-night therapy withdrawal. Sleep 1995; 18: 195-201.

17. Jenkinson C, Stradling J, Petersen S. Comparison of three measures of quality of life outcome in the evaluation of continuous positive airways pressure therapy for sleep apnoea. J Sleep Res 1997; 6: 199-204.

18. Kiely JL, McNicholas WT. Bed partners' assessment of nasal continuous positive airway pressure therapy in obstructive sleep apnea. Chest 1997; 111: 1261-1265.

19. Lojander J, Maasilta P, Partinen M, Brander PE, Salmi T, Lehtonen H. Nasal CPAP, surgery, and conservative management for treatment of obstructive sleep apnea syndrome. A randomised study. Chest 1996; 110: 114-119.

20. Redline S, Adams N, Strauss ME, Roebuck T, Winters M, Rosenberg C. improvement of mild sleep-disordered breathing with CPAP compared with conservative therapy. Am J Respir Care Med 1998; 157: 858-865.

21. Engleman H, Martin SE, Deary IJ, Douglas NJ. Effect of CPAP therapy on daytime function in patients with mild sleep apnoea/hypopnoea syndrome. Thorax 1997; 52: 114-119.

22. Miilman RP, Fogel BS, McNamara ME, Carlisle CC. Depression as a manifestation of obstructive sleep apnea: reversal with nasal continuous positive airway pressure. $J$ Clin Psychiatry 1989; 50: 348-351.
23. Edinger JD, Carwile S, Miller P, Hope V, Mayti C. Psychological status, syndromatic measures, and compliance with nasal CPAP therapy for sleep apnea. Percept Mot Skills 1994; 78: 1116-1118.

24. Derderian SS, Bridenbaugh RH, Rajagopal KR. Neuropsychological symptoms in obstructive sleep apnea improve after treatment with nasal continuous positive airway pressure. Chest 1988; 94: 1023-1027.

25. Bedard MA, Montplaisir J, Malo J, Richer F, Rouleau I. Persistent neuropsychological deficits and vigilance impairment in sleep apnea syndrome after treatment with continuous positive airway pressure. J Clin Exp Neuropsychol 1993; 15: 330-341.

26. Bortolotti M. Laryngospasm and reflex central apnoea caused by aspiration of refluxed gastric content in adults. Gut 1989; 30: 233-238.

27. Kerr P, Shoenut JP, Millar T, Buckle P, Kryger MH. Nasal CPAP reduces gastroesophageal reflux in obstructive sleep apnea syndrome. Chest 1992; 101: 1539-1544.

28. Follenius M, Krieger J, Krauth MO, Sforza F, Brandenberger G. Obstructive sleep apnea treatment: peripheral and central effects on plasma renin activity and aldosterone. Sleep 1991; 14: 211-217.

29. Krieger J, Follenius M, Sforza E, Brandenberger G, Peter JD. Effects of treatment with nasal continuous positive airway pressure on atrial natriuretic peptide and arginine vasopressin release during sleep in patients with obstructive sleep apnoea. Clin Sci 1991; 80: 443-449.

30. Baruzzi A, Riva R, Cirignotta F, Zucconi M, Cappelli M, Lugaresi E. Atrial natriuretic peptide and catecholamines in obstructive sleep apnea syndrome. Sleep 1991; 14: 8386.

31. Krieger J, Petiau C, Sforza E, Delanoe C, Hecht MT, Chamouard V. Nocturnal polyuria is a symptom of obstructive sleep apnea. Uro Int 1993; 50: 93-97.

32. Hedner J, Darpo B, Ejnell H, Carlson J, Caidahl K. Reduction in sympathetic activity after long-term CPAP treatment in sleep apnoea: cardiovascular implications. Eur Respir J 1995; 8: 222-229.

33. Santamaria JD, Prior JC, Fleetham JA. Reversible reproductive dysfunction in men with obstructive sleep apnoea. Clin Endocrinol 1988; 28: 461-470.

34. Poceta JS, Dalessio DJ. Identification and treatment of sleep apnea in patients with chronic headache. Headache 1995; 35: 586-589.

35. Ulfberg J, Carter N, Talback M, Edling C. Headache, snoring and sleep apnoea. J Neurol 1996; 243: 621-625. 